\title{
Only in Canada, eh?
}

A good friend of mine is a 'man on the inside'. He is a thoughtful civil servant and I believe what he tells me. We share stories when we meet at parties, and over many years have had an ongoing 'information exchange'. We always talk about the health system. He knows what I think about it.

We met again last week.

"I'd like you to meet a friend of mine," he said. "He'll meet you in the underground parking garage at Sick Kids. Go to section $6 \mathrm{~F}$ and wait for him, Tuesday this week, at 6:30 pm."

So I did. I pulled into the underground parking lot driving down and down. I've never got used to these places - they're huge, but I still get a bit claustrophobic. I pulled into a space, killed the engine and waited.

I heard a tap on the window by my left ear.

"Open the back door," said a voice.

As I unlocked the door, I saw an ordinary sort of man, in a raincoat, tweed hat, and dark glasses. He got into the back seat.

"Look," he said, "I know this is a little unusual, but our mutual friend has told me your opinion of the health service, and we thought you might be able to give us some advice about a certain matter. Off the record of course.

"Reduction mammaplasty has been a problem to us for years, but especially last year. You plastic surgeons are doing too many of them. It's the most popular operation you do. The problem is that you are doing so many of them, that the hospital costs are astronomical. We have to find a way to save money, since the province this year alone has a ten billion dollar deficit. It's not plastic surgeon's fees that are the problem, it's the hospital costs that are ruining us."

"I know it's not surgeon's fees that are too high," I said. "If you told American plastic surgeons we in Canada got $\$ 810$ for a bilateral breast reduction, they wouldn't believe it. And that's Canadian dollars!"

"Even so," he said, "as an experiment, we decided to reduce the fee for breast reduction even lower to see if fewer would be done, as a way to reduce hospital costs, because we thought you plastic surgeons would finally get disgusted and either stop doing the operation, or do more of them as cosmetic operations."

"Doesn't the Ontario Medical Association set the fees?" I asked.

"They do, but the GPs raised their fees to gain parity with the specialists, and lowered your fees in the process. You see, we set the amount of money to be spent, and the association sets the fees, so we can tell doctors who don't like the fee to talk to their association, not to us. A neat ploy to deflect responsibility, don't you think?"

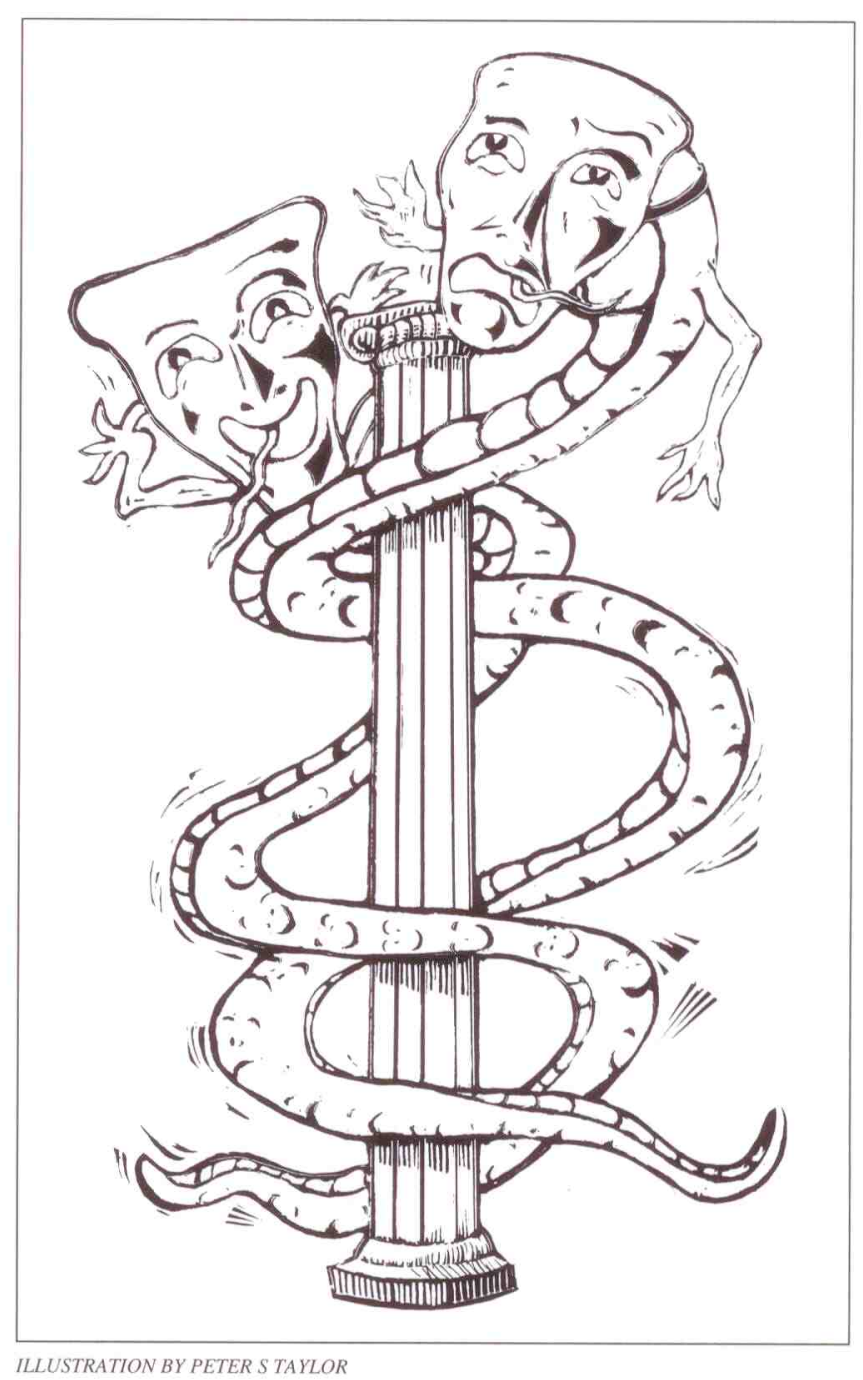

I had long suspected just this, but I had never heard anyone put it this way, so I asked, "Why are you telling me this?"

"We need to know at what fee plastic surgeons will stop doing this operation," he said.

"What happened when you lowered the fee to $\$ 756.00$ from $\$ 810.00$ ?" I asked.

"Plastic surgeons did more breast reductions!" he said. "We were amazed. We thought we had discovered a new formula. Lower the fee, and get more productivity. Of course we hated having more productivity because it meant more expense."

"Does this phenomenon have a title yet?" I asked.

"Of course," he said proudly. "We call it the inversereverse equation. The lower the fee, the more surgery is done. Would you do this operation for nothing?"

"Of course not," I said, a little put out by the silliness of the question. 
"Exactly," he said. "We at the ministry have to figure out at what fee most plastic surgeons will stop doing the operation. We are lowering the fee $5 \%$ a year just to see what this level is. Next year the fee will be $\$ 700$, and the year after $\$ 650$. We'll watch the numbers of breast reductions you do. What do you think will happen?"

"Before I met you, I thought I knew, but now I'm not so sure," I said. "Look, why not suggest this to your colleagues at the Ministry of Health. Why not have the government pay for all those things that are life threatening, and all the other things not necessary for life such as breast reductions, can be paid for by health insurance that the patient can buy if they want to.

"But you know we made private health insurance illegal in 1968," he said.

"Yes, I know you did, and to get yourself out of this mess, you'd better make it legal again."

"How are we going to do that, when we already promised the voters that all health care would be free?" he said quietly.

I was prepared for the question. "All you have to do," I said, "is to tell the politicians to say that you have developed a new and better way of doing things - a way that will preserve the social fabric of the country. The government will pay for those things that are life threatening, and people will be free to buy whatever insurance they want to pay for those things that make the quality of life better. The unions could negotiate that as an employee benefit in their next contract. That way you are guarding the 'sacred trust' you have sworn to protect, although personally, I think health care should be pragmatic, not religious. By 'pragmatic' I mean, if it works, do it."

"What a good idea," he said. "This could save us hundreds of millions of dollars. I'm glad we had this little conversation - we should do it again sometime." He paused. "I have to go," he said.

"What should I call you?" I asked.

"How about Deep Pharynx," he laughed. "Listen, this has been a real meeting of the minds. I hope we can meet again soon. We could use your help with many problems at the ministry."

With that he was gone, leaving me to ponder.

Dear reader;

This meeting never took place, though I sometimes wish it had. Readers unfamiliar with the Canadian system need to know that it is a civil offence in Canada for doctor and patient to agree on a fee that is more than the government benefit for a medically necessary service.

The penalty for the doctor is a fine of $\$ 1,000$, and the same fine for the patient! To date, a patient has never been fined.

It makes me wonder if any country with such a fear of the potency of capitalism practised by the individual can ever do well in a world economy.

Only in Canada, eh? 